\section{Career \\ progression \\ on a \\ shoestring}

Anonymous

Returning to work after one or more periods of maternity/paternity leave brings with it a host of considerations related to how that work will take shape or form now that life has changed so much. There can suddenly feel like a lot more work and a lot less time to do it in. Plus there are now additional 'constraints' (beautiful, grubby, lovely, and demanding constraints) on previously 'free' time which could have been dedicated to work.

Career progression can seem particularly problematic, especially as progression typically involves taking on extra roles or responsibilities (which require more time) and delivering on these (which also requires significant time and dedication) at a time when there have never been more demands and stress placed on your seemingly measly 24 hours a day (e.g. O'Laughlin \& Bischoff, 2005; Bianchi \& Milkie, 2010; Aiston \& Jung, 2015).

So how can a new mum or dad (perhaps for the second or third time) still make some headway with career progression on such a tight time budget?

\section{Ingredients}

- Pen and paper or laptop.

- Your University strategy document.

- A good pinch of reflection.

- Some quality coaching and mentoring.

\section{Method}

1. Consider your professional work values - what are the ultimate ways in which you desire to behave in your working environment? It can help to undertake a values clarification activity to do this. A coach or mentor can help you focus on these.

2. Consider how these values underpin your overall vision and mission as a professional (i.e. what is it you are working towards or trying to make a difference to?)

3. Identify the main objectives of your working role (e.g. research; external engagement; learning and teaching; leadership and management).

4. Identify the goals and action plans which will allow your role to grow in the direction you want to. Ask yourself what you find most enjoyable about your job.

5. As long as your goals and actions are broadly in line with the overall strategy of your employer, you can be sure that you are progressing your career, while developing in an organic way that matches and you don't have to compromise on your core values. 


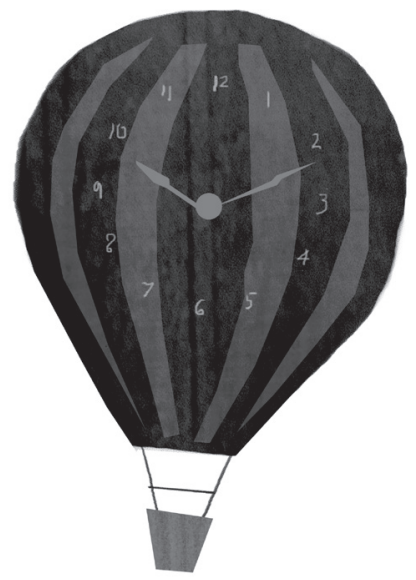

You can find the University of Edinburgh mission statement at http://www.ed.ac.uk/about/ mission-governance/mission

Different schools within the University offer a range of mentoring (see Mentoring Connections website: http://www.ed.ac.uk/humanresources/learning-development/ mentoring-connections) and coaching opportunities (see Career coaching for individuals). In fact, $R(D) S V S$ (the Royal (Dick) School of Veterinary Studies) and the Roslin Institute offer specific mentoring for those returning from parental leave. The Schools of Molecular, Genetic and Population Health Sciences, and Clinical Sciences have a "buddying" system for those returning from parental leave to get support from peers.

\section{Cook's tip}

It can be helpful to think of your career progression as a 'tree' with your values as the nutrients in the soil, your vision and mission forming the trunk, your objectives as the main branches and your goals and action plans as the smaller branches and leaves. You can even have more than one tree and grow your own orchard!

\section{Warning}

Beware of the trend for employment negotiations to favour men compared to women (Bowles et al., 2005; Castilla \& Benard, 2010) and note that this does not have to be the 'norm' (Golding \& Rouse, 2000; Bohnet et al., 2012; Bowles et al., 2005). 